\title{
A LEITURA CRÍTICA E A FORMAÇÃO DO GRADUANDO EM LETRAS DA UNICRUZ
}

\section{Antonio Escandiel de Souza}

\section{INTRODUÇÃO}

A cada dia que passa evidencia-se mais a dificuldade que jovens e adolescentes encontram no momento de realizar uma leitura crítica. Isso ocorre porque a maior parte do tempo destinado às aulas de língua portuguesa é consumido com atividades que envolvem a gramática, e assim, o aluno vai ficando longe do processo de leitura e elaboração de textos.

Como resultado disso, temos um contingente de alunos que, já no Ensino Médio, não conseguem elaborar um pensamento com clareza, muito menos realizar uma leitura crítica. O quadro se agrava ainda mais quando constatamos, através de observações empíricas, que alunos graduandos em Letras demonstram ainda não terem desenvolvido aquela última habilidade. Considerando-se esse quadro, bem como a constatação da necessidade de formarmos pessoas com consciência crítica, decidimos operacionalizar uma atividade em nível de terceiro grau - Curso de Letras (licenciatura) envolvendo a investigação-ação educacional numa oficina de leitura crítica. A metodologia adotada pressupôs o dialogismo democrático e aberto entre todos os envolvidos, visando à detecção e resolução de problemas advindos da prática acadêmica do próprio grupo.

Houve, de nossa parte, uma preocupação constante com a formação daqueles que, na qualidade de futuros docentes em língua portuguesa, serão orientadores em leitura. Com esta preocupação, buscamos uma metodologia que oportunizasse ao licenciando em Letras um espaço onde houvesse a dialética entre ação e reflexão. Nessa perspectiva, a pesquisa-ação mostrou-se como a forma mais adequada para deflagrar essa relação dialética, e a via concreta para sua realização, a oficina de leitura segundo KLEIMAN (1996) e ANDER-EGG (1990).

Para o desenvolvimento da atividade proposta exploramos textos publicitários diretos - cartas de mala-direta - a fim de atingirmos o objetivo da oficina: promover um incremento na competência de leitura do graduando em Letras da Universidade de Cruz Alta, aliado à conquista de uma consciência crítica.

\subsection{DELIMITANDO O PROBLEMA}

Através da constatação da necessidade que o educador possui de formar profissionais com consciência crítica, buscamos desenvolver as habilidades de leitura crítica no terceiro grau, curso de Letras, a partir de um procedimento interacionista e da metodologia da pesquisa-ação. Como mencionamos anteriormente, exploramos para isso, textos publicitários diretos - cartas de maladireta - através de uma oficina de leitura. 


\subsection{CONTEXTUALIZANDO A PESQUISA}

Inicialmente contatamos a coordenação do curso de Letras da Universidade de Cruz Alta e relatamos a intenção de operacionalizarmos uma oficina de leitura com os alunos. Decidimos, então, que a atividade de pesquisa seria desenvolvida com os alunos do segundo semestre do curso. Definimos isso após contato com alguns professores da turma, os quais nos afirmaram que a turma apresentava deficiências no que concerne à leitura crítica. Ressaltamos, aqui, que a Universidade, por sua vez, manifestou total apoio e incentivo à nossa pesquisa.

\section{FUNDAMENTAÇÃO TEÓRICO-METODOLÓGICA}

Para o desenvolvimento de nosso trabalho, elegemos um corpus composto por sete cartas de mala-direta. Para a seleção dessas cartas, levamos em consideração os diferentes tipos de cartas de mala-direta.

A seleção do corpus citado justifica-se pela necessidade de conhecermos as estratégias de marketing direto na tentativa de comercialização de produtos para não nos tornarmos alvos fáceis desses apelos.

Com o objetivo de explorar e assim iniciar o conhecimento de cada tipo de maladireta, bem como analisar criticamente as estratégias de marketing empregadas pelos publicitários, as peças foram discutidas e analisadas uma a uma com 0 grupo participante da oficina.

\subsection{EXPLICITANDO O MÉTODO}

Considerando as questões metodológicas como extremamente relevantes, no que diz respeito à leitura crítica e a sua prática pedagógica, na atividade desenvolvida na UNICRUZ foi proposta uma ação que oportunizasse a reflexão e a implementação de soluções para o desenvolvimento de instrumentais cognitivos. A oficina de leitura apresentou-se, então, como o elemento desencadeador da reflexão-ação no processo de leitura crítica. Afinal, segundo KLEIMAN (1996, p. 10) "é neste espaço que a aprendizagem é construída na interação de sujeitos cooperativos que têm objetivos comuns".

A atividade que desenvolvemos seguiu, então, os passos da investigação-ação educacional, com o objetivo de promover um incremento na competência de leitura da graduando em Letras da UNICRUZ, aliado à conquista de uma consciência crítica.

A metodologia da investigação-ação pode ser entendida como uma orientação à prática cotidiana. Para uma pesquisa ser assim denominada, CARR \& KEMMIS (1988) afirmam que ela deve apresentar dois objetivos essenciais: a melhora e o interesse. Porém, além de apresentar esses dois objetivos essenciais, os autores comentam que para haver investigação-ação, são necessárias três condições mínimas: 
A primeira, que um projeto seja planejado com o tema da prática social, considerada como uma forma de ação estratégica suscetível de melhoramento; a segunda, que tal projeto recorra a uma espiral de elos de planejamento, ação, observação e reflexão, estando todas essas atividades implantadas e interrelacionadas sistematicamente e autocriticamente; a terceira, que o projeto envolva os responsáveis da prática em todos e cada um dos momentos da atividade, ampliando gradualmente a participação no projeto para incluir os outros afetados pela prática, e manter um controle colaborativo do processo. (CARR \& KEMMIS, 1988, p. 177, tradução nossa )

Em todos os encontros houve o empenho em desenvolver estratégias de leitura de textos publicitários diretos (cartas de mala-direta), oportunizando aos participantes momentos de reflexão sobre a leitura, aqui entendida como ação interpretativa sobre os textos, objetivando melhorá-la. Ao final de cada encontro houve um espaço aberto onde foram salientadas as impressões ou quaisquer outras manifestações consideradas significativas, inclusive sugestões dadas pelos participantes da oficina. Cada participante teve a oportunidade de voltar-se para sua própria ação, realizando, assim, uma auto-reflexão, uma análise de seu próprio desempenho com vistas a uma possível alteração de comportamento, influenciando também, se possível, os colegas a mudarem seus desempenhos em leitura. Essa forma de ação, conforme definição de CARR \& KEMMIS (1988, p. 174) aproxima-se da pesquisa-ação:

A pesquisa-ação (action research) é, sensivelmente, uma forma de indagação auto-reflexiva que empreendem os participantes em situações sociais no intuito de melhorar a racionalidade e a justiça de suas próprias práticas, seu entendimento das mesmas e as situações dentro das quais elas têm lugar.

A metodologia da investigação-ação educacional aqui adotada seguiu as etapas básicas de CARR \& KEMMIS (1988), o que facultou ao grupo auto-reflexivo a promoção cíclica e em espiral dos passos de planejamento, ação, observação e reflexão retrospectiva, reflexão esta que desembocava num replanejamento recorrente dos aspectos das ações que consensualmente deixavam de corresponder às expectativas.

\section{DISCUSSÃO DE RESULTADOS PARCIAIS OBTIDOS}

Em nossa oficina de leitura os dados obtidos foram sendo analisados a fim de avaliar os progressos apresentados pelo grupo no que se refere à competência de leitura. Para isso, metodologia, dados e marco teórico formaram um todo articulado, pois como afirma SERRANO (1990, p. 118) "A interpretação dos resultados deve integrar-se a um marco teórico preciso, para poder propor ações aportunas a serem executados".

Todas as atividades propostas ao grupo tinham como objetivo estimular a Zona de Desenvolvimento Proximal, teoria sócio-interacionista de Vygotsky segundo a qual, o contato com pessoas mais capazes oportuniza o desenvolvimento individual, construindo-o na passagem das práticas assistidas para as práticas 
internalizadas.

A interação social é, segundo VYGOTSKY (1987), fundamental no processo de desenvolvimento, uma vez que esse é socialmente construído. Nesse sentido, uma proposta de trabalho em grupo como a nossa oficina de leitura viabiliza a interação centrada na resolução de problemas e, conseqüentemente, 0 desenvolvimento, conforme podemos comprovar através de uma entrevista gravada no dia 22.10.99, quando um participante da oficina manifestou-se dizendo: "Eu confesso que achei bastante difícil realizar essa tarefa. Acho que sozinha eu não conseguiria, mas através da troca de idéias com minha colega, as coisas ficaram mais claras".

Essa observação, entre outras, claramente vai de encontro à teoria vygotskyana. Por isso, em nosso trabalho na UNICRUZ, procuramos priorizar a interação entre os participantes da oficina.

Para a análise das informações, optamos por realizar um rastreamento, comparando os dados de início, meio e final de oficina. A partir desses dados, procuramos definir basicamente três fatores, dois dos quais referem-se à competência em leitura e o terceiro, à conquista da autonomia, respectivamente. Os três fatores considerados foram: organização semântico-pragmática do texto, identificação dos atos de fala constitutivos das estratégias pragmáticas do texto e desenvolvimento da competência metacognitiva sobre os processos de leitura. Porém, no presente artigo estamos apresentando um apanhado geral dos três fatores.

Através de uma atividade desenvolvida no dia 05.11.99, a qual solicitava que os alunos descrevessem como era sua competência de leitura no início da oficina comparando com a etapa final do trabalho, uma acadêmica participante manifestou-se fazendo a seguinte afirmação:

No início da oficina, fazíamos uma leitura acrítica, ou seja, não chegava propriamente a ser uma leitura, como agora podemos perceber. Não tentávamos extrair os sentidos de um texto esgotando todas as possibilidades semânticas e pragmáticas, como fazemos atualmente. Agora já nos consideramos mais preparados para ler realmente não só as cartas de mala-direta, mas também outros tipos de textos, de forma bastante crítica, analisando as possíveis intenções do autor.

Tal afirmação fala a favor de um ganho na competência de leitura. Através desse ganho de competência, os acadêmicos conquistaram a segurança não só na leitura e interpretação de cartas de mala-direta, como também em outros textos de diferentes tipologias.

Como um dos objetivos da presente pesquisa-ação foi contribuir com a formação de futuros professores da área de Letras, já podemos pensar em resultados satisfatórios, pois através de uma entrevista gravada no dia 11.11.99, uma acadêmica sugeriu que a oficina continuasse, argumentando que para eles, enquanto futuros professores, era uma atividade de suma importância. A mesma 
aluna afirmou ainda, que após todas as atividades desenvolvidas na oficina, sentia-se mais segura para trabalhar leitura com alunos.

\section{CONCLUSÃO}

Tomando-se a experiência de modo panorâmico, seus resultados indicam que através do procedimento interacionista aqui adotado e da metodologia da pesquisa-ação, conseguimos promover um incremento na competência de leitura do graduando em Letras da Universidade de Cruz Alta - UNICRUZ. Isso tornouse possível em razão de termos favorecido a discussão e o diálogo entre o grupo, oportunizando, assim, um espaço aberto para a reflexão sobre a ação: a oficina de leitura.

Como instrumento de pesquisa, a oficina mostrou-se de significativa importância, e como tão bem a definiu ANDER-EGG (1990, p. 10), “... é uma forma de ensinar e sobretudo aprender, mediante a realização de algo que se executa em grupo".

Apesar do resultado fundamental alcançado ter sido um incremento notável na capacidade de ler autônoma e criticamente textos publicitários de marketing direto, seria necessário mais algumas semanas de trabalho, pois devido aos encontros serem quinzenais, em apenas duas horas, e também do semestre letivo contar com vários feriados, não foi possível desenvolver muitas atividades que já haviam sido planejadas. Os próprios acadêmicos sentiram essa necessidade, conforme constatou-se através dos relatos aqui apresentados.

Tornou-se evidente que a interação entre os indivíduos oportuniza situações de aprendizagem. Sob o ponto de vista de Vygotsky, companheiros mais capacitados, sejam eles colegas ou professores, desempenham importante função no desenvolvimento cognitivo de pessoas menos capacitadas: estímulo e reforço. Essa prática trabalha dentro da Zona de Desenvolvimento Proximal e leva o educando à conquista da autonomia. Claramente foi o que observamos na oficina de leitura, cujo relato e discussões parciais estão aqui registrados.

\section{BIBLIGRAFIA:}

ANDER-EGG, E. Repensando la investigación-acción participativa:comentário, críticas

y sugerencias. México: El Ateneo, 1990.

CARR, W. ; KEMMIS. S. Teoria crítica de la ensenanza. Barcelona: Martinez Roca, 1988.

KEMMIS, S. ; McTAGGART, R. Como planificar la investigación-acción. Barcelona:

Laertes, 1988.

KLEIMAN. A. B. Texto e leitor: aspectos cognitivos da leitura. Campinas: Pontes, 1992.

Oficina de leitura: teoria e prática. Campinas: Pontes, 1996.

LEFFA, V. J. Aspectos da leitura. Porto Alegre: Sagra, 1996.

LEWIN, K. Action-research and Minority Problems. In: Journal of Social Ussues, v. 2, 
n. 4, 1946, trad. Maria Cristina Salazar.

LURIA, A. R. Desenvolvimento cognitivo: seus fundamentos culturais e sociais. São Paulo: Ícone, 1990.

MOITA LOPES, L. P. Oficina de lingüística aplicada. São Paulo: Mercado de Letras, 1996.

MOLL, L. C. Vygotsky e a Educação: implicações pedagógicas da psicologia sócio-histórica. Porto Alegre: Artes Médicas, 1996.

OLIVEIRA, M. K. Vygotsky: apendizado e desenvolvimento Um processo sócio-histórico. São Paulo: Scipione, 1997.

RABAÇA, C.A.; BARBOSA, G. Dicionário de comunicação. São Paulo: Ática, 1987.

RICHTER, M. G. A publicidade e o seu funcionamento: algumas consideraçõe. Letras, Santa Maria: UFSM, n. 9, p. 93-111, jul./dez. 1994.

SERRANO, M. G. P. Investigación-acción: aplicaciones al campo social y educativo. Madrid: Dykinson, 1990.

THIOLLENT, M. Metodologia da pesquisa-ação. São Paulo: Cortez, 1996. VYGOTSKY, L S. Formação social da mente. São Paulo: Martins Fontes, 1984. . Pensamento e linguagem. São Paulo: Martins Fontes, 1987. 